\title{
Article
}

\section{Establishing a Taphonomic Research Facility in the United Kingdom}

Cross, Peter Andrew, Simmons, Tal Linda Ileen, Cunliffe, Rachel Elizabeth and Chatfield, Lee Keith

Available at http://clok.uclan.ac.uk/32006/

Cross, Peter Andrew ORCID: 0000-0003-1812-5664, Simmons, Tal Linda Ileen, Cunliffe, Rachel Elizabeth ORCID: 0000-0002-1585-9112 and Chatfield, Lee Keith (2010) Establishing a Taphonomic Research Facility in the United Kingdom. Forensic Science Policy \& Management: An International Journal, 1 (4). pp. 187-191. ISSN 1940-9044

It is advisable to refer to the publisher's version if you intend to cite from the work. http://dx.doi.org/10.1080/19409041003653095

For more information about UCLan's research in this area go to http://www.uclan.ac.uk/researchgroups/ and search for < name of research Group>.

For information about Research generally at UCLan please go to http://www.uclan.ac.uk/research/

All outputs in CLoK are protected by Intellectual Property Rights law, including Copyright law. Copyright, IPR and Moral Rights for the works on this site are retained by the individual authors and/or other copyright owners. Terms and conditions for use of this material are defined in the policies page.

\section{CLoK}

Central Lancashire online Knowledge www.clok.uclan.ac.uk

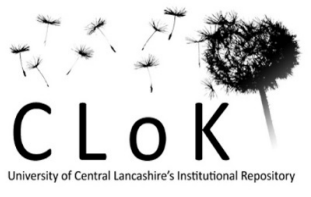




\title{
Establishing a Taphonomic Research Facility in the United Kingdom
}

\author{
Abstract \\ In May 2009, the University of Central Lancashire, UK, launched TRACES \\ (Taphonomic Research in Anthropology- Centre for Experimental Study). This \\ facility uses animal models in taphonomic research. The use of animal models \\ facilitates wider studies of factors influencing decomposition than the low replicate \\ numbers common to human cadaver studies. The establishment of dedicated facilities \\ to carry out taphonomic research is long and complex. Whether the facility uses \\ human cadavers, as in the United States, or animal models, as here in the UK, the \\ issues that arise can be common to both. These include commitment of resources, \\ local community concerns and planning and legal issues. However, the use of animal \\ models also raises additional ethical and legislative concerns. These include \\ environmental impact, animal welfare, bio-security and disposal activities. This article \\ discusses the processes undertaken during the establishment of a taphonomic facility \\ using animal models in the UK and demonstrates the level of commitment, \\ enthusiasm and perseverance required.
}

\section{Keywords}

Forensic Anthropology, Taphonomy, Decomposition 


\subsection{Introduction}

A number of facilities using human cadavers in taphonomic research operate in the USA. These include the Anthropological Research Facility at the University of Tennessee, as well as smaller volume facilities, such as those at Texas State University, Western Carolina University and Wichita State University.

Taphonomic research within the UK and Europe has to date focused on the use of animal models, notably the domestic pig, Sus scrofa (Turner and Wiltshire 1999, Dekeirsschieter et al. 2009, Charabidze et al. 2009, Matuszewski et al. 2008, Özdemir and Sert 2009). Research using animal models continues to provide valuable insights into the processes of decomposition and the factors that influence it. This research also provides important information on local climatic influences and entomological data that are relevant to the conditions found in the UK. Whilst studies using human cadavers might be preferable in terms of their direct relevance to forensic cases, animal models facilitate much larger studies of the variables that may influence decomposition as greater numbers of animals are available for use at one time. In human cadaver studies, numbers of replicates are limited, leading to less robust statistical analysis. Much past and current research on decomposition using human cadavers has produced anecdotal findings based on single case studies or experiments with low replicate numbers (Rodriguez and Bass1983, Mann et al. 1990, Bass, 1997, Schroeder et al. 2002, Vass et al. 1992).

Taphonomic research using animal models can contribute significantly to forensic knowledge. However, the use of a site for animal decomposition studies raises 
attendant legislative and ethical issues. Careful consideration of these issues is of vital importance for the successful establishment and use of such a facility.

\subsection{Selecting the Site}

Land newly acquired for taphonomic research is likely to be either agricultural land or a 'brown field' (disused industrial or commercial site) site. In selecting such a site in the UK, it is important to be cautious of any land located within a specific designated area, such as National Park, National Nature Reserve, Ramsar Sites, Special Areas of Conservation, Sites of Special Scientific Interest, Biological Heritage Sites and Sites of Outstanding Natural Beauty. Sites within these areas are subject to increased restrictions on planning and usage.

Agricultural land may be used for other purposes for up to 28 days per calendar year* and thus short term, temporary taphonomic research projects may be carried out under this provision. The acquisition of land for use as a permanent site for taphonomic research requires a formal change of land use. This necessitates an application to the local planning authority. A number of issues will be considered by the local authority in assessing such an application. The employment of professional planning consultants can greatly assist in the preparation and submission of a planning application. Consultants are particularly useful in dealing with the potential effects on the proposed usage from the perspective of national and local planning strategies.

\footnotetext{
* The Town and County Planning (General Permitted Development) Order 1995. SI No 418
} 
When considering the size and location of a site, it is essential to assess the impact of the work undertaken there on nearby dwellings or other human activities. Public rights of way, such as footpaths and bridleways, commonly run alongside or across agricultural land, and these rights of way cannot be changed. Minor rights of way may not be marked on maps and it is essential to establish their location, either by seeking such information from the local authority or from the current landowner. Privacy for the site and its activities is also desirable. The geography of the site will determine whether it is overlooked from any other location. In some areas of the UK it is difficult to find areas of agricultural land that are not overlooked from some vantage point, particularly in more hilly regions. Both public and private rights of ways, including public roads with roadside picnic areas or golf courses, may provide a good view of a site, even from some distance away. Additional tree planting and landscaping of a site may be advisable in such cases.

The actual or perceived nuisance of a research site to the general public must be considered and the local authority will look at this aspect very seriously with respect to a planning application. Selecting a site with no immediate public access may still attract concerns relating to potential views, odours and vermin. Our experience to date indicates that smells produced from carcass surfaces deposits are unlikely to cause a nuisance if they are some distance from the public. Likewise, the attraction of additional vermin, including insects, is unlikely to be significant or to create a nuisance. However, these aspects need to be considered in the context of the actual site and any plan needs to address each of these issues should they arise. 
The location of a taphonomic research site, particularly a new one, can potentially lead to a considerable degree of media interest. Any local authority planning applications that are associated with the proposed new facility will be made public. This often has to be balanced against the desirability of site anonymity, as using animal remains can raise sensitivities and lead to problems with site security. Most academic institutions will have public/media relations specialists and it is important to work with these individuals to pre-empt and plan for any local media interest that may arise. Press release documents may be prepared well in advance and provided to the media if they become aware of the planning application and its implications. In this manner, a correct statement of the facility's purposes and impact can be made public without necessitating interviews and potentially ill-thought out (or off the cuff) unfortunate comments being made by staff unaccustomed to dealing with the press.

The value of full consultation with local residents and parish/ local councils cannot be underestimated. This can assist greatly in obtaining support for a planning application. This process begins with talking to neighbours about the proposed activities of the site. In doing so, it should be demonstrated that potential concerns have already been considered and, where applicable, appropriate action has been taken to deal with these. Typical areas of concern include the increased activity of vermin, smell nuisance, noise, pollution and attraction of unwanted attention, either through public curiosity or from protest groups. Neighbours of a site planned in a remote location may also be concerned about increased vehicle traffic. A response to these concerns which demonstrates that they have already been considered will increase neighbourly confidence in the proposals and reduce any perceived nuisance to local citizens. If a proposed site falls within the boundaries of a lower tier council to the planning 
authority, such as a parish council, it is advisable to attend a local meeting to present proposed plans. This continued involvement of the local community will help in allaying concerns and in building a relationship of trust and cooperation. Such thorough consultation will be looked upon favourably by the planning authority and will minimise the potential for public objections being lodged against the planning application.

\subsection{Groundwater Pollution}

The geology of much of the UK means that it possesses aquifer potential (British Geological Survey, 2009) and thus provides a source of water for human and animal use. When planning to deposit animal carcasses, consideration must be given to the requirements of the relevant Environmental Protection Legislation, notably The Groundwater Regulations $1998^{\dagger}$. A Groundwater Vulnerability Assessment must be carried out and it is the responsibility of the proposed site owner to undertake this assessment. Initial advice should be taken from the Environment Agency ${ }^{\ddagger}$ regarding the site's geology and thus how vulnerable it is to pollution from carcass deposits. The Environment Agency Operational Instruction for on- farm burial of carcasses ${ }^{\S}$, The Environment Agency Operational Instruction for Animal By-Product Regulation $^{* *}$ and the Water, Air and Soils Codes of Good Agricultural Practice ${ }^{\dagger \dagger}$ provide the necessary technical methodology for assessing and managing a site and must be followed.

\footnotetext{
$\dagger$ The Groundwater Regulation 1998. S I No. 2746

$\$$ The Environment Agency operates in England and Wales. The Scottish Environment Protection Agency operates in Scotland.

$\S$ Environment Agency Operational Instruction 537_06, On-farm burial of carcasses - technical assessment. This document is used for EA staff guidance.

** Environment Agency Operational Instruction 131_03, Animal By-Product Regulation and Environment Agency Work. This document is used for EA staff guidance.

${ }^{\dagger}$ Protecting our Water, Soil and Air: A Code of Good Agricultural Practice for farmers, growers and land managers. ISBN 9780112432845
} 
Early contact with the Environment Agency is an important first step in assessing a site's suitability. The full assessment will include identification of private water supplies and other physical features, such as watercourses, field drains, springs, boreholes and shake/swallow holes. Identification of source protection zones, soil leachability and aquifer status are also included within this assessment. Full consultation and advice should be taken from the Environment Agency relating to this assessment. Regulations require that carcass deposits be a minimum distance from certain physical features. Surface deposits and the base of any burial pits must also be at least $1 \mathrm{~m}$ above the water table. It should be noted that permanent burial requires an Environment Agency Licence, as this is classed as disposal. However, if the remains are exhumed after completion of research, such a licence is not required.

\subsection{Use of Animals}

Potential sensitivity to the use of animals for research is obviously an important consideration. All research utilising animal remains must be approved by the institution's relevant ethics board. It is not usual to allow animals to be bred specifically for taphonomic research, and the production of the proposal for the ethics committee usually requires that the source of animals is clearly defined. The use of pigs will allow sourcing from herds that have been reared for commercial meat production and are destined to be slaughtered for food; this is usually sufficient to meet the requirements of this portion of the guidelines for the ethical use of animals in the UK (Nuffield Council on Bioethics, 2005). This also applies when pigs are sourced directly from a farm. The use of other animal species may not require this 
consideration. For example, wild rabbits which are culled annually as a practical agricultural pest control measure are permitted for this purpose.

If animals are sourced from a farm, veterinary advice is essential. Animal Health, which is an Executive Agency of the Department for Environment, Food and Rural Affairs (DEFRA) ${ }^{*}$ will provide advice on issues relating to animal by-products, and an approval issued by Animal Health under the Animal By-Products Regulations $2005^{\S \S}$ is necessary. This allows the use of animal by-products for diagnostic, educational or research purposes. Under this legislation, animal by-products are defined as any material (from relevant species) which is not, or is no longer, intended for human consumption. This does not include wild animals. Pigs sourced directly from a farm, or carcasses sourced from a meat supplier, are thus classed as Animal By-Product. Under these regulations, animal by-product is categorised according to the risk it poses to animal and human health. This type of material is classed as 'Category 2'.

On-farm slaughter of pigs must be carried out by a veterinary surgeon or licensed slaughterer, subject to the regulatory provisions. ${ }^{* * *}$

\subsection{Bio-Security}

Events of recent years surrounding disease outbreaks in the UK, in particular of Foot and Mouth Disease as well as Avian Flu and Blue Tongue, highlight the importance of appropriate bio-security measures. This involves good hygiene practice to help

\footnotetext{
Animal Health acts across the UK on behalf of the Department for Environment, Food and Rural Affairs in England, the Scottish Executive Environment and Rural Affairs Department and the National Assembly for Wales Agriculture Department.

$\$ \S$ Regulation 25 and 26 of the Animal By-Product Regulations 2005 (SI No. 2347) (SI No.1293 Wales) and Article 23 of Regulation (EC) No 1774/2002

${ }^{* * * *}$ The Welfare of Animals (Slaughter and Killing) Regulations 1995 (SI No. 731) and amendments (SI Nos. 400, 3820, 3272, 402) (SSI Nos. (Scotland) 238, 13)
} 
prevent the spread of disease. If animal carcasses are removed directly from a farm and transported to another location, minor lapses in bio-security may have potentially serious and damaging consequences. Veterinary advice on these issues is vital. It is important for the background disease status of any herd to be known and that clinical inspection of animals is undertaken by a veterinary surgeon prior to slaughter. Onfarm bio-security measures should be under veterinary control and must be strictly adhered to. These measures include the use of appropriate personal protective equipment (PPE), personal hygiene and adherence to disinfection procedures, both for PPE and vehicles. In addition, the use of body bags and suitable leak proof containment of carcasses during transport, along with any additional measures deemed necessary by veterinary advice, should ensure that bio-security issues are adequately dealt with. A comprehensive bio-security protocol is an essential element of any such research site and is likely to be scrutinised by the local planning authority.

\subsection{Disposal}

The transport of pig carcasses from the supplier and post-research remains of pig carcasses (or other species covered by the Animal By-Product Regulations 2005) are required to be disposed of in accordance with The Animal By-Product (Identification and Staining) Regulations 1995 (as amended) ${ }^{\dagger \dagger \dagger}$. This involves the staining of remains with the food dye, Brilliant Black BN (E151), and subsequent transportation to a DEFRA approved animal by-product renderer or incineration facility. Local companies offer this waste carrier service to abattoirs and butchers and a list of approved carriers is available from local authority trading standards departments.

†† The Animal By-Product (Identification and Staining) Regulations 1995 SI No. 614 and amendments ( SI Nos. 2073, 1619, 283, 1472, 3231, 53). 
Transportation of Animal By-Products must be in suitable leak proof containers and the vehicle must display signage indicating 'Category 2 Animal By-Product - Not for Animal Consumption'. Under these regulations, anything not suitable for animal consumption does not have to display signage as; 'unfit for human consumption'. Some research facilities may also opt to dispose of animal remains as clinical waste.

On-site incineration offers an alternative means of disposal. Small scale incinerators, approved by DEFRA for the incineration of animal by-products, are available with burn rates of less than $50 \mathrm{~kg} / \mathrm{hr}$. Incinerators under this burn rate are adequate for the quantity of remains most taphonomic research facilities would produce and are exempt from the need for local authority planning permission, although their installation must be inspected and approved by DEFRA. Thorough records must be kept of material incinerated as Animal Health will carry out routine inspections of the facility and records. Category 2 animal by-product ash is a 'controlled waste' under The Environmental Permitting (England and Wales) Regulations 2007 ${ }^{\mathrm{Ht}}$, and must be disposed at a permitted landfill site or disposed of or recycled by other means approved by the Environment Agency. Paragraph 28 of these regulations permit an exemption whereby pig and poultry ash can be spread on land where the ash is produced, subject to Environment Agency approval. Full details of regulations governing incinerator use can be obtained from Animal Health ${ }^{\S \S}$.

\footnotetext{
W* The Environmental Permitting (England and Wales) Regulations 2007 replaced the Waste Management (England and Wales) Regulations 2006 SI No. 3538 (commonly referred to as the Agricultural Regulations 2006.

$\S \S \S$ REGULATION (EC) No 1774/2002 laying down health rules concerning animal by-products not intended or human consumption \& The Animal By-Products (England) Regulations 2005. S.I.2005/2347 Controls on Low Capacity Animal Carcase Incineration Plants - Version 2.2
} 


\subsection{Summary}

The establishment of a university taphonomic research facility involves considerable investment of time and resources. Support from the directorate level is essential and a number of departments or schools within the university will be involved. In our experience the process can be greatly facilitated by assigning responsibility to a single individual who can coordinate and liase with the university departments, external agencies and local community. Environmental, animal by-product, animal welfare and planning legislation are complex and a thorough knowledge of these is important and will aid liaison with regulatory bodies, and facilitate progress.

The views of local residents and the wider public are a major issue and can be highly influential in local authority planning decisions. This factor is common to the establishment of any facility of this nature, and has been a major factor in the failure to establish more taphonomic facilities in the US (Melbye and Hamilton 2009). Although the use of human cadavers in the US may raise concerns of a different type to the use of animals in the UK, many issues concerned with the establishment of such a facility are common to both. However, much important taphonomic research needs to be carried out in order to establish the post-mortem interval with greater accuracy; with commitment, adequate resources, enthusiasm, hard work and determination, such facilities can be established.

In May 2008, the School of Forensic and Investigative Sciences at the University of Central Lancashire, UK, began the process of searching for a potential site. Such a site was located in early August 2008. The site was purchased in January 2009. Further site assessments, external liaison and consultation, as outlined above, began, and in March 2009, the university was in a position to lodge a planning application for 
change of use. Planning approval was granted on $8^{\text {th }}$ May 2009 and the University of Central Lancashire was able to launch the first site in the UK specifically dedicated to taphonomic research, known as TRACES (Taphonomic Research in Anthropology Centre for Experimental Study). The work doesn't stop here of course. Continuous investment of resources and scientific rigour are necessary, not only to establish, but also to develop a centre of excellence of this kind.

\section{Acknowledgements}

The authors would like to thank John Richards, David Price and Trudi Robson from the University of Central Lancashire, Adrian Baker- UCLAN Veterinary Advisor, Gonzalo Sanchez-Cabezudo - Veterinary Officer, Animal Health Executive Agency of the Department of Food, Environment and Rural Affairs (DEFRA), Peter Carter Environment Agency (England and Wales), and Matthew Birkinshaw from DPP Planning Consultancy.

\section{References}

Bass, W.M. Outdoor decomposition rates in Tennessee. 1997 In: Haglund WD, Sorg, MH, Eds. Forensic Taphonomy: The Postmortem Fate of Human Remains. Boca Raton:CRC Press 181-6.

British Geological Survey, www.bgs.ac.uk/britainbeneath/land_introduction.html (Last Accessed July 2009) 
Charabidze, D., Bourel, B., Hedouin, V., Gosset, D. 2009. Repellent effect of some household products on fly attraction to cadavers, Forensic Science International, 189 (1-3):28-33.

Dekeirsschieter, J., Verheggen, F.J., Gohy, M., Hubrecht, F., Bourguignon, L., Lognay, G. and Haubruge, E. 2009. Cadaveric volatile organic compounds released by decaying pig carcasses (Sus domesticus L.) in different biotopes, Forensic Science International, 189 (1-3):46-53.

Mann, R.W., Bass, W.M., Meadows, L. 1990. Time Since Death and Decomposition of the Human Body: Variables and Observations in Case and Experimental Field Studies, J Forensic Sci. 35 (1):103-111

Matuszewski, S., Bajerlein, D., Konwerski, S., Szpila, K. 2008 An initial study of Insect succession and carrion decomposition in various forest habitats of Central Europe, Forensic Science International, 180 (2-3):61-69.

Melbye, J., Hamilton, M.D. 2009. Creating an Open-Air Forensic Anthropology Human Decomposition Research Facility, Presented at American Academy of Forensic Sciences Meeting, Denver, Colorado, USA, February 2009. 
Nuffield Council on Bioethics, The Ethics of Research involving Animals Report Published May 2005.

http://www.nuffieldbioethics.org/go/ourwork/animalresearch/publication_178.html Accessed July 2009.

Özdemir, S., Sert, O. 2009. Determination of Coleoptera fauna on carcasses in Ankara province, Turkey, Forensic Science International, 183 (1-3):24-32.

Rodriguez, W.C., Bass, W.M. 1983. Insect Activity and its Relationship to Decay Rates of Human Cadavers in East Tennessee J Forensic Sci 28 (2):423-432.

Schroeder, H., Klotzbach, H., Oesterhelweg, L., Püschel, K. 2002. Larder beetles (Coleoptera, Dermestidae) as an accelerating factor for decomposition of a human corpse, Forensic Science International, 127 (3):231-236.

Turner, B. and Wiltshire P. 1999. Experimental validation of forensic evidence: a study of decomposition of buried pigs in a heavy clay soil. Forensic Science International, 101:113-122.

Vass, A.A., Bass, W. M., Wolt, J.D.,Foss, J.E., Ammons, J.T. 1992. Time Since Death Determinations of Human Cadavers Using Soil Solution. J Forensic Sci 37 (5):1236-1253. 